\title{
Study of Jiangxi Cuisine under a Cultural Background and Its English Translation
}

\author{
Julin Xu, Xiangying Tu \\ Jiangxi College of Application Science and Technology, Nanchang, Jiangxi, 330100
}

Keywords: Jiangxi Cuisine, Cultural Background, English Translation

\begin{abstract}
Translation is a kind of exchange of intercultural information, whose essence is the dissemination of information. The translation of the characteristic gourmet culture is to optimize the output of the cultural information in the food through decoding and coding. By studying various factors influencing translation strategies under the perspective of culture, this paper analyzes the advantages and disadvantages of domestication and foreignization in cultural translation, and realizes the effective English translation of the culinary culture so as to explore practical and feasible translation methods of the culinary culture.
\end{abstract}

\section{Introduction}

China is a big eating country with a long history of food culture. A wide variety of Chinese dishes, cooking techniques rich, named stress and full of cultural connotation. At present, China and all other countries in the world are increasingly cooperating in various fields and the food and beverage culture in China has also been widely spread around the world. However, the translation of Chinese names is not standardized at present, and some dishes have various methods of translation. This has brought some obstacles to the flourishing of Chinese food culture and the exchanges between China and the world. Therefore, it is necessary to study the translation method of Chinese name. Chinese cuisine pay attention to color and shape Xiangxiang mutually beneficial, since ancient times there is "food is not too refined, not tired of" argument. This is reflected in the knife method, cooking methods and other aspects. Chinese food not only pay attention to the method, the name is very particular about. They are either named after raw materials and cooking methods, such as dried kidney beans or braised beef; or they are named after the color of the dish, such as sweet potato and hot and sour cabbage; or the animals and plants that are popular with the Chinese and symbolize good fortune, Such as Longfeng Chengxiang and Hibiscus chicken slices; some are named after places such as Yangzhou fried rice and Chengdu chicken; or named after people such as Dongpo Meat and Kung Pao Chicken; or named after historical allusions, Rice noodles. Chinese cuisine has so many naming methods and so rich cultural connotations that it brings certain difficulties to the translation of Chinese names. Here are some commonly used methods of Chinese name translation, with a view to the Chinese food culture to make a contribution to carry forward.

\section{Jiangxi Cuisine and Its Potential}

The "Tenth Five-Year Plan" period is an important period in which Jiangxi's economy and society have been developing rapidly and the rise of Central China has taken shape. Under the guidance of Deng Xiaoping Theory and the important thought of Three Represents, Jiangxi Provincial Party Committee and Government established and implemented the scientific concept of development, emancipated the mind, pioneered and innovated, and made remarkable achievements in the province's reform and opening up as well as socialist modernization. Among them, the catering industry has played an important role in the economic and social development of Jiangxi, especially in the promotion of the social consumer market, and has played a decisive role in the development of a new leap forward in the rise of central Jiangxi. Both the theory and practice of economics prove that the growth of the catering industry is positively related to the growth of the 
national economy and promotes each other. The rapid development of the national economy, fast-growing restaurant industry; the same rapid development of the restaurant industry is also effectively driving the development of the national economy. With the sustained and rapid economic and social development in Jiangxi Province, the income levels of urban and rural residents have risen significantly, and the demand for catering, leisure and social consumption has been on the rise. The mass consumption market by families has been increasing constantly. The catering market driven by red tourism and leisure tourism Grow rapidly. Gan Po diet speak color, seeking texture, heavy flavor, fresh and tender, reputable one. "Three cups of chicken", "Dongpo meat", "Yongxin dog meat", "Hing tau tofu", "Artemisia bactrian hairtail" and other famous dishes well-known. Gan Po diet green health, ecological Tiancheng. Poyang Lake is a large wetland of water system. It is one of the six wetlands with rich biological diversity. It not only gives birth to abundant aquatic plants and plankton resources, but also is a rare bird's paradise in the world. "Pohu birds, know how much fly when the clouds and the sun, the lake fell grass time" is a true portrayal of the ecological environment of Poyang Lake. "Poyang Lake in a grass, on the table is a treasure," is a heart-to-heart compliment Gan Gan earth green healthy diet. Gan Po This "a lake water" is the Jiangxi Po earth, and even the optimization of the Earth's ecological environment, but also the development of Jiangxi Province, a green eco-food resources treasure. Gan Phe diet also has impressive achievements in modern times. \# \$\% \& Year, Gan Po dishes won the Octagon Nostalgia in Beijing's national dishes exhibition activities, "Three cups of chicken", "Yongxin dog meat", "two-color egg mushrooms" and other food diners alike. (Year Thirteenth China Chef Festival, Gan Po dishes won the cooking masters at home and abroad and cooking industry authority highly praised) Today, the world renowned "Three Chickens," and Known as the "treasure on the dinner table," the Poyang Lake Artemisia selengensis grass has been selected as the main menu of the Olympic Games and has enjoyed a good reputation. With the continuous deepening of ecological civilization construction in Jiangxi Province, the cultural connotation of Jiangxi diet continues to evolve and deepen. Cultural values and characteristics of the times will continue to be explored and highlighted. The catering industry based in Jiangxi Poyang will certainly play a greater economic and social role in the process of building an overall well-to-do society.

\section{Study on English Translation of Chinese Dish Names}

According to the food materials, food preparation workers, cooking seasoning, dish dishes composed of Chinese dishes, it is best to use literal translation method, the objective and realistic description of the dishes, so that foreign friends on the food materials knife, cooking Process at a glance. As a result, the author summarizes the following five translation formats: the main material as the central word, and then prepositions with adjuncts. Such as Eel with Chives, Duck with Chinese Caterpillar Fungus, Diced Chicken with Cashew Nuts, Pork Shred swith Green Pepper, and the like. It is worth mentioning that the rice bowl series is usually translated with the raw rice + over rice pattern, for example, Pork Chop over Rice. Main ingredients as the central word, and then use the preposition in or with the connection sauce and seasoning. Such as Fish with Chili Bean Sauce, Shredded Pork with Sweet Bean Paste, Spare Ribs in Sweet and Sour Sauce, Duck Webs with Mustard Sauce, Diced Rabbit with Orange Peel and so on.

Cooking method and raw materials constitute the Chinese name of the dish can be used literally translated way, the corresponding cooking method translated, and then the main ingredients of food as the central word. Such as Twice-cooked Pork, Sautéed Water Spinach, Braised Pork Feet, Soft-fried Prawns, Liquor-soaked Chicken, and the like. Chinese cuisine out of exquisite selection of materials, taste fine, sophisticated cooking, but also stress the beautiful food. For many Chinese dishes named for cooking or cooking containers, you can use raw materials as the center, then preposition in or with the connection to cook or hold containers. For example, the series of casserole: Fish Head in Casserole; Claypot series: House Special Seafood in Clay Pot; hot pot series: Tripe in Hot Pot; steamer series: Beef in Small Steamer; Leaf pack series: Chicken Wrapped in Lotus Leaves; Sticky Rice with Red Bean Paste Wrapped in Reed Leaves.

There are many Chinese names based on historical allusions and names to be named, deep 
cultural implication, if bluntly "Buddha jumping wall" literally translated into Buddha Jumping over the Wall, "Beggar Chicken" translated Beggar's Chicken, "Mapo bean curd "Translated as Pock-marked Grandma's Bean-curd, will only make foreign patrons foggy, big appetite. I believe that for this type of dish name, you should first literally translated the meaning of the name of the dish, and then use the dash to briefly explain the history of the names or legends and the origins of this dish, and then explained in the brackets the cooking method and the actual use of the dishes Ingredients to reproduce the source of the cultural information. Beggar's Chicken- a name aftera legend telling a beggar smeared a chicken all over with clay and threw it into a fire. After a long while, he removed it and cracked it open, finding it already baked into a delicious dish (Buddha Jumping over the Wall- A name after a legend saying that even Buddha could not resist the temptation of the dish and jumped over the wall of the temple to taste it (stewedshark fins with assorted seafood), Mapo Tofu: Ma PoBean- curd- a name after its inventor, a pock- markedwoman in Szechwan province (ground pork with bean curd in chili sauce).

Chinese food culture is profound and profound. Many famous snack foods can not find the equivalent cultural semantic symbols in English, thus forming a vacancy in the vocabulary of inter-lingual communication. "Due to the lack of vocabulary in inter-lingual communication, the content of the translated information is less than the original to carry the amount of information due to the amount of translation, often can be introduced and borrowed approach ". For example, many traditional Chinese phonetic transcriptions based on the pronunciation of Cantonese preserved their original Chinese flavor and became commonplace translation methods such as Dim Sum, Chow Mein, Lo Mein, Chow Fan (fried rice), Wonton (wonton), Chop suey (chop suey, fried assorted) and so on.

With the exchange and exchange of human society, Chinese restaurants are blooming all over the world. The principle of alienated translation, which aims to spread the source language and culture information, has been widely used in the translation of Chinese names. By means of transliteration and annotation, we can not only introduce the traditional Chinese food culture symbols to target readers, but also understand the needs of western readers through annotation. I heard a "foreigner" a la carte "Jah Tsay Row Shuh" at a Chinese restaurant in the United States. When I opened the menu, the mustard pork was translated as Jah Tsay Row Shuh (shredded pork with Szechwan - style preserved vegetables). The translation not only accords with Westerners' pronunciation habit, but also conforms to the upsurge of sinology in the world. Many of the specialties of Chinese cuisine are translated by transliteration, such as Zong Zi- pyramid- shaped sticky rice wrapped in reed leaves, You Tiao-deep fried twisted dough stick, Guo Tie- pot stickers), The regional figures let food shape, material, system of fresh paper. It is worth noting that many translations of dumplings, dumplings, glutinous rice dumplings, wontons and other specialties made with bread stuffing are often used in many translations. I think transliteration can translate and differentiate these types of foods in China The role of specialty foods. Such as Jiao Zi-dumpling stuffed with vegetable and meat fillings, Shaomai - steamed dumplings with pork and sticky rice fillings, Tang Yuan-dumplings made of sticky rice flour served in soup, Wonton dumpling soup.

Traditionally, domestic English translation experts consider more about the acceptability of common language thinking, psychological habits, information needs and expressions of English speaking audiences when translating food culture. This complete or more alienated translation strategy can easily lead to the lack of full acceptance of the new culture to be accepted by the audience and to the real exchange between cultures, thus rendering the translation unsatisfactory. At present, the translation of food culture either does not pay attention to the promotion of the theory, or concludes that the specific method of translation is not generalized. When doing cultural output translation, we should adhere to the principle of "three closeness" in translation, that is, close to the reality of China's development, close to the needs of foreign audiences for Chinese information, and close to the thinking habits of foreign audiences. English translation of food culture should be based mainly on the target language, English translation of English grammar, syntax, lexical should be in line with the use of English norms. Although with the deepening of the process of economic globalization, the politics, economy and culture all over the world are characterized by English as 
the main medium, English is gradually becoming the news, publicity signs, road signs, product introduction, city introduction, business promotion and tourism Introduction and other aspects of the main foreign language, but in the English translation can not blindly rely on naturalization strategy, over-inclined to Westerners thinking patterns and behavior, language habits, to break the international community has its own unique vocabulary and images, Introduce more cultural products and services with distinctive Chinese characteristics so that people in the world can learn more about China from the perspective of food culture. For this reason, it is necessary to pay attention to the use of alienation strategies in the translation of food cultures related to the subjects of folklore, allusions and culture.

\section{Conclusions}

As a special cultural symbol, distinctive cuisine is not only an image hardware but also a person's senses, providing services to people and even image software, reflecting certain service attitude and living standards. With the increasing pace of globalization, English translation of distinctive gourmet culture is an effective way for international dissemination of Chinese culture. Exporting culinary culture through effective English translations will, to some extent, contribute to the widespread dissemination of profound Chinese culture and create a better. The international cultural atmosphere, enhance the international image of the country, to better integrate into the world.

\section{Acknowledgements}

Study on the Translation of Names of Jiangxi Food Names in the Perspective of Cultural Adaptation Theory in Youth Project of Humanities and Social Sciences in Jiangxi Province in 2015 (YY1531)

\section{References}

[1] Tang Hongmei. English evaluation of vocational college evaluation system [J]. Examination Weekly, 2009 (2): 119-120.

[2] Jin Yan. Multivariate Evaluation of Experiential College English Teaching [J]. Foreign Language Teaching and Research, 2010 (1): 70-78.

[3] Li Lihua, Luo Hong, Zou Jin. Higher vocational English curriculum evaluation system reform of the research and practice: module teaching based on the English curriculum evaluation system [J]. Science and Education Department, 2007 (3): 122-123.

[4] Zhou Jing. An Empirical Study on Formative Assessment of College English [J]. College English, 2012 (1): 118-124.

[5] Qiao Ping. Chinese food name classification and English translation method [J]. Yangzhou University, Journal of cooking, 2004, (2), 48. 